\title{
Article \\ Healthcare Workers' Knowledge and Perception of the SARS-CoV-2 Omicron Variant: A Multinational Cross-Sectional Study
}

\author{
Akshaya Srikanth Bhagavathula 1,*(D), Mohammadjavad Ashrafi Mahabadi ${ }^{2} \mathbb{D}$, Wubshet Tesfaye ${ }^{3}$, \\ Kesavan Rajasekharan Nayar ${ }^{4}$ (D) and Vijay Kumar Chattu 5,6,7 (D)
}

check for updates

Citation: Bhagavathula, A.S.;

Mahabadi, M.A.; Tesfaye, W.;

Nayar, K.R.; Chattu, V.K. Healthcare Workers' Knowledge and Perception of the SARS-CoV-2 Omicron Variant: A Multinational Cross-Sectional Study. Healthcare 2022, 10, 438. https://doi.org/10.3390/ healthcare10030438

Academic Editor: Tamas Alexy

Received: 27 January 2022

Accepted: 23 February 2022

Published: 25 February 2022

Publisher's Note: MDPI stays neutral with regard to jurisdictional claims in published maps and institutional affiliations.

Copyright: (C) 2022 by the authors. Licensee MDPI, Basel, Switzerland. This article is an open access article distributed under the terms and conditions of the Creative Commons Attribution (CC BY) license (https:// creativecommons.org/licenses/by/ $4.0 /)$.
1 Institute of Public Health, College of Medicine and Health Sciences, United Arab Emirates University, Al Ain 17666, United Arab Emirates

2 Faculty of Medicine, Iran University of Medical Sciences, Tehran 14665-354, Iran; mjamahabadi@gmail.com

3 Sydney Pharmacy School, The University of Sydney, Sydney, NSW 2006, Australia; wubshet.tesfaye@sydney.edu.au

4 Global Institute of Public Health, Ananthapuri Hospitals and Research Institute, Thiruvananthapuram 695024, India; krnayar@gmail.com

5 School of Public Health, University of Alberta, Edmonton, AB T6G 1C9, Canada; vijay.chattu@mail.utoronto.ca

6 Center for Transdisciplinary Research, Saveetha Institute of Medical and Technological Sciences, Saveetha University, Chennai 600077, India

7 Department of Community Medicine, Faculty of Medicine, Datta Meghe Institute of Medical Sciences, Wardha 442107, India

* Correspondence: akshaypharmd@gmail.com

\begin{abstract}
In late November 2021, a new SARS-CoV-2 Variant of Concern (VOC) named Omicron (initially named B.1.1.529) was first detected in South Africa. The rapid spread of the SARS-CoV-2 Omicron variant became globally dominant, and the currently available COVID-19 vaccines showed less protection against this variant. This study aimed to investigate healthcare workers' (HCWs) knowledge and perceptions about the novel SARS-CoV-2 Omicron variant. A cross-sectional anonymous electronic survey concerning the SARS-CoV-2 Omicron variant was conducted among HCWs during the second week of January 2022. The survey instrument was distributed through social media among HCWs to explore awareness (2 items), knowledge (10 items), source of information (1 item), and perceptions (10 items). Respondents who answered $\geq 80 \%$ of the items correctly were considered as having good knowledge and perception. A total of 940 of the $1054 \mathrm{HCW}$ participants completed the survey (response rate: $89.1 \%$ ); they had a mean age of $31.2 \pm 11.2$ years, most were doctors $(45.7 \%)$, and most were from Asia (64.3\%). All the participants were aware of the SARS-CoV-2 Omicron variant (100\%). Only 36.3\% attended lectures/discussions about Omicron and used news media to obtain information. Only a quarter of the HCWs demonstrated good knowledge $(24.3 \%, n=228)$ and perception $(20.6 \%)$ about Omicron. However, while significant differences were observed in the knowledge and perception among HCWs, only a small proportion of doctors exhibited good knowledge $(13 \%)$ and perception $(10 \%)$ about the Omicron variant. HCWs who had participated in training/discussion related to the Omicron variant were more likely to have higher knowledge and perception scores (odds ratio: 1.80; 95\% confidence interval: 1.04-3.11). As the SARS-CoV-2 Omicron variant spreads rapidly across the globe, ongoing educational interventions are warranted to improve knowledge and perceptions of HCWs.
\end{abstract}

Keywords: SARS-CoV-2; Omicron; COVID-19; awareness; knowledge; attitude; perceptions; prevention; survey; health professionals

\section{Introduction}

According to statistics from the John Hopkins University's Coronavirus Resource Center, as of February 19, 2022, SARS-CoV-2 has infected over 421 million people globally, with over 5.8 million deaths from coronavirus in 2019 (COVID-19) [1]. In late November 
2021, a new SARS-CoV-2 Variant of Concern (VOC) named "Omicron" (initially named B.1.1.529) was first detected in South Africa [2]. The rapid spread of the Omicron variant suggests that it may become globally dominant. In addition, the currently available COVID19 vaccines have shown little to no protection against the SARS-CoV-2 Omicron variant [3].

The Omicron variant is less severe than earlier Variants of Concern (VOCs) $[4,5]$. Nevertheless, the rapid transmissibility of this variant continued to have a knock-on effect on services for other health conditions, leading to overwhelmed health systems across the globe. The risks of hospitalization, intensive care unit admission, and mortality, while considerably lower than were observed with the Delta variant [6], are still significant, largely affecting people who are not vaccinated [6]. Importantly, the existing vaccines provide the greatest protection against the Delta variant [7-9] and provide some level of protection against Omicron, especially in preventing severe symptoms that lead to hospitalization [10]. A longer time having elapsed from the first to the second dose was particularly associated with an increased risk of a symptomatic form of COVID-19 [11]. While more research and data are needed to fully understand this, evidence in certain settings suggests that the booster dose is effective in curbing the impact of Omicron $[10,12,13]$.

Healthcare workers (HCWs), as frontline responders to the pandemic and members of a community highly affected by the VOC Omicron, have been key players in mitigating the effect of the COVID-19 pandemic and its consequences, as well as in implementing preventative measures suitable to evolving variants of interest. Several research articles have assessed various health specialties and populations' knowledge, awareness, attitude, perceptions, and preventive practices towards COVID-19 [14-18]. However, given the evolving nature of the COVID-19 pandemic, updated knowledge of the epidemiological relevance of mutated versions of SARS-CoV-2 is imperative to understand the virulence and risk of transmissibility associated with emerging variants, as well as the effectiveness of existing public health and social measures. More importantly, assessing the knowledge of HCWs about the effective tools available to prevent newly emerging variants, the relevance of existing diagnostic tools in detecting such variants, and the efficacy of the range of vaccines currently in use is fundamental in reducing the multifaceted impact of the disease. As such, this survey aims to explore the knowledge and perception of HCWs concerning the SARS-CoV-2 Omicron variant to consolidate the evidence surrounding this new variant.

\section{Materials and Methods}

A cross-sectional web-based survey was conducted using Qualtrics ${ }^{\mathrm{TM}}$ (www.qualtrics. com), and a survey instrument was distributed to obtain responses from HCWs globally during the second week of January 2022.

\subsection{Content of the Survey Instrument}

A 24-item survey instrument was developed using the information of the World Health Organization (WHO) and the US Centers for Disease Control and Prevention (CDC) on the SARS-CoV-2 VOC Omicron [19-21]. The survey was divided into four sections. The first section aimed to collect general demographic data such as age, gender, country, and profession. The second section explored the awareness (two items) and the personal sources of reliable information such as news, social media, health authority websites, and family/friends. The sources of information were scored using a four-point Likert scale (1-least used to $4-$ most used). The third section explored the understanding of SARSCoV-2 VOC and their origins (five matching questions), specifically knowledge of the Omicron variant such as its origin (one item), symptoms (one item), transmissibility (one item), and risk prevention (one item), and the importance of COVID-19 vaccination (one item). The fourth section aimed to explore the perceptions of the SARS-CoV-2 Omicron variant and asked whether the respondents (yes/no/not sure): (1) believe the COVID-19 vaccine provides protection from the Omicron variant, (2) consider the COVID-19 vaccine booster dose important, and (3) know the influence of SARS-CoV-2 mutations on patient management. In addition, seven true or false questions were asked about the Omicron 
variant concerning vulnerability (one item), travel restrictions (two items), testing (one item), treatment (one item), protective measures (one item), and vaccination program (one item) (Supplemental File S1: survey questionnaire).

\subsection{Validity of the Survey Tool}

At first, the developed questionnaire and the materials used were distributed through email to five experts from different geographic regions to comprehensively assess the content domains of the questionnaire (using a scale of 1 - poor to 5-excellent) and were encouraged to critically appraise the survey tool. The readability of the survey tools was assessed by distributing the questionnaire and materials to 15 randomly selected faculty members and asking them to rate the readability of each question from 0 to 100 (0-30: confusing; 31-50: difficult; 51-70: standard; 70-90: easy; and 90-100: very easy). Refinements were made, and the questions were reorganized to facilitate comprehension, following experts' comments. Finally, the questionnaire was pilot tested with 15 randomly selected HCWs to assess clarity, relevance, and acceptability. These participants were not included in the research.

\subsection{Sample Size}

Sample size was calculated using the $G^{*}$ Power statistical software (version. 3.1.9.7; Heinrich-Heine-Universität Düsseldorf, Düsseldorf, Germany) [22]. The power analysis results indicated that an $80 \%$ power would be obtained with $95 \%$ confidence when 767 participants were included in the study (Supplemental: Figure S1). Considering 20-25\% dropouts and participants not responding or giving incomplete information, we invited over one thousand individuals to participate in the survey.

\subsection{Recruitment}

The study questionnaire was distributed online to the study population through a Uniform Resource Locator Link of Qualtrics using social media sites such as WhatsApp, Facebook, LinkedIn, Telegram, Twitter, and personal emails of the HCWs. Furthermore, the survey link was advertised in health professional groups to reach the target population and was opened from 12 January to 15 January 2021. The survey tool was limited to one response of the questions per participant, and the survey instrument was made available for $30 \mathrm{~min}$ to read, comprehend, and answer all the questions.

\subsection{Scoring}

Each knowledge response was scored as "2" (correct) and "0" (wrong), with scores ranging from 0 to 20. Participants' overall knowledge scores were categorized using a modified Bloom's criteria cutoff point [23] as good if the score was between 80 and 100\% (16-20), moderate if $60-79 \%(12-15)$, and poor if $<60 \%$ (total score $<12$ ).

Perceptions towards the Omicron variant were assessed using ten questions, and the responses were graded as a 3-point Likert scale, an agreement scale ranging from ' 2 ' for correct to ' 0 ' neutral. The overall level of perception was categorized using modified Bloom's criteria as good if the score was 80-100\% (16-20 points), neutral if the score was $60-79 \%(12-15)$, and a misperception if the score was less than $60 \%$ (<12 points).

\subsection{Statistical Analysis}

The collected data were coded, validated, and analyzed using SPSS software version 24 (IBM Corporation, Armonk, New York, NY, USA). Descriptive statistics were used to summarize the information and presented as mean \pm standard deviation or $95 \%$ confidence intervals $(\mathrm{CI})$, median and range, and calculated frequencies and proportions. ANOVA test was used to compare the participants' knowledge and perceptions about the Omicron variant. Comparison of the distribution of responses was evaluated for the following categories: (1) male vs. female, (2) doctors vs. other HCWs, (3) attended training/lectures vs. not attended, (4) participant from developed vs. developing countries according 
to the United Nations, using the Mann-Whitney U-test. Between-group comparison of knowledge and perception score variation across their health specialties was performed using analysis of covariance (ANCOVA). The covariates were age, sex, survey completion time, attended training/discussions regarding Omicron variant, and from developed and developing countries. The Chi-square test evaluated the differences between the subgroups overall knowledge and perception scores across the subgroups. Univariate and multivariate logistic regression analyses were performed to identify the factors associated with good knowledge and perception. Crude and adjusted odds ratios (OR) with 95\% CI were calculated. Statistical significance was set as two-sided $p \leq 0.05$.

\subsection{Ethical Consideration}

The study was conducted following the Checklist for Reporting Results of Internet E-Surveys (CHEERIES) guidelines [24] (Supplemental file: Table S1). Ethical approval was obtained from the Ethical Review Committee of Ananthapuri Hospitals and Research Institute, India (AHRI/EC/Dec/2021). Participants were informed about the objective of the study, and their participation was completely voluntary, with no financial compensation. Electronic informed consent was shown on the initial page of the survey. Confidentiality of the information was assured throughout the study by making participants' information anonymous and asking them to provide honest answers.

\section{Results}

\subsection{Overview}

A total of 940 of the 1054 HCWs that participated completed the survey questionnairea fulfillment rate of $89.1 \%$, including $539(57.3 \%)$ men and $401(42.7 \%)$ women. Most participants were below 30 years of age $(n=530,56.4 \%)$, and the mean age of the study cohort was $31.2 \pm 11.2$ years. Most participants were doctors $(n=430,45.7 \%)$ or medical students $(n=225,23.9 \%)$ and most were from Asia $(n=604,64.3 \%)$. The participants' average time to finish the survey was $5.9 \pm 3.9 \mathrm{~min}$. Participant characteristics are summarized in Table 1. All the HCW participants agreed that they had heard about the SARS-CoV-2 Omicron variant, but only $36.3 \%(n=341)$ had the opportunity to attend lectures or discussions related to the Omicron variant.

Table 1. Characteristics of study participants $(\mathrm{N}=940)$.

\begin{tabular}{lcc}
\hline \multicolumn{1}{l}{ Sex } & Variable & Frequency (\%) \\
\hline & Male & $539(57.3)$ \\
\hline Age (mean \pm SD) & Female & $401(42.7)$ \\
\hline & $18-29$ & $31.2 \pm 11.2$ years \\
\hline Participant's Location & $30-39$ & $530(56.4)$ \\
\hline & $\geq 40$ & $194(20.6)$ \\
\hline & Asia & $216(23)$ \\
\hline Africa & $604(64.3)$ \\
\hline South America & $137(14.6)$ \\
\hline North America & $125(13.3)$ \\
\hline Oceanic & $39(4.1)$ \\
\hline
\end{tabular}


Table 1. Cont.

\begin{tabular}{|c|c|}
\hline Variable & Frequency $(\%)$ \\
\hline \multicolumn{2}{|l|}{ Profession } \\
\hline Doctors & $430(45.7)$ \\
\hline Medical students & $225(23.9)$ \\
\hline Pharmacists & $120(12.8)$ \\
\hline Nurses & $60(6.4)$ \\
\hline Allied health & $105(11.2)$ \\
\hline I Heard of SARS-CoV-2 Omicron & $940(100)$ \\
\hline I Attended Lectures/Dissions About Omicron & $341(36.3)$ \\
\hline Survey Completion Time (mean \pm SD) & $5.9 \pm 3.9 \mathrm{~min}$ \\
\hline
\end{tabular}

\section{SD: standard deviation.}

\subsection{Source of Information}

When asked about the participants' source of reliable information about the Omicron variant, the primary source mentioned was news media and government websites (Figure 1). About one-third of the participants reported that they often used news media (TV/video, newspapers, radio, and magazines), and a quarter (24.3\%) relied on the websites of national and multinational health institutions (e.g., $\mathrm{WHO}, \mathrm{CDC}, \mathrm{MOH}$, etc.) to obtain information on the Omicron variant. Furthermore, 39\% of the participants sometimes held discussions on the Omicron variant with family and friends.

- Least used

- Sometimes

- More often

- Most used
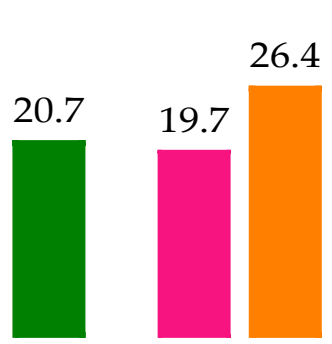

29.7

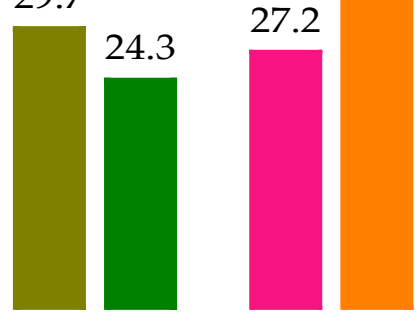

\section{Sources of information on SARS-CoV-2 Omicron variant}

Figure 1. Healthcare workers' sources of reliable information on the SARS-CoV-2 Omicron variant.

\subsection{SARS-CoV-2 Variants of Concern}

When the HCWs were asked to identify the origins of various WHO-designated SARS-CoV-2 VOCs, a high proportion identified the Omicron variant (B.1.1526) as having originated from South Africa but were not able to identify the origins of other SARS-CoV-2 VOCs correctly (see Figure 2 for more details). 


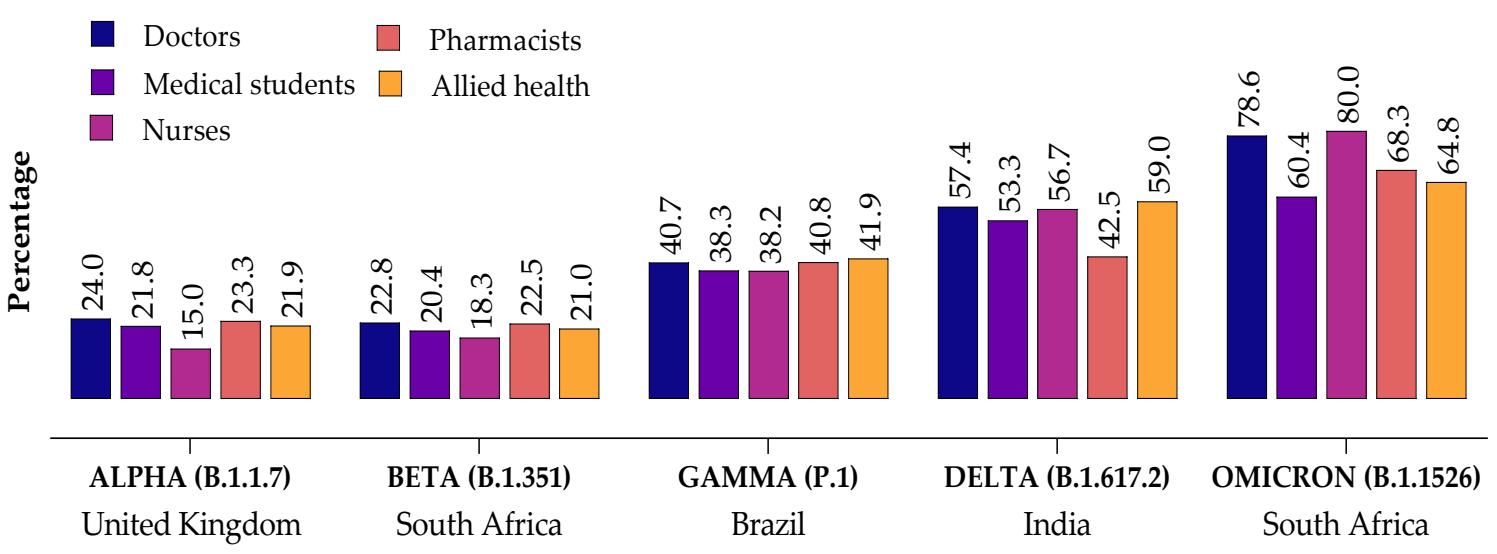

Figure 2. Healthcare workers correctly identified WHO-designated SARS-CoV-2 Variants of Concern (VOCs) and their countries of origin.

\subsection{Knowledge and Perceptions about SARS-CoV-2 Omicron Variant}

We identified significant variance in the knowledge and perceptions between the HCWs and significant differences across HCWs when stratified by sex, doctors and other HCWs, developed and developing countries, and attended vs. did not attend lectures or discussions. Table 2 shows the level of HCWS knowledge and perceptions about the SARS-CoV-2 Omicron variant. Over $90 \%$ of the HCWs agreed that the Omicron variant could be transmitted to all age groups (91.4\%), that following preventive measures $(92.8 \%)$ can offer protection against the Omicron variant, and that taking two doses of a COVID-19 vaccine is important $(89.1 \%)$. A higher proportion $(80 \%)$ of doctors correctly identified that skin rash is not a symptom of Omicron compared to medical students $(72.4 \%)$ and allied health professionals $(69.5 \%)$.

Overall, only $20.1 \%(n=194)$ of the HCWs exhibited good perceptions about the Omicron variant. Only $32.6 \%$ of the doctors believed that the currently available COVID-19 vaccines, and $40.2 \%$ that taking vaccine booster doses, offer protection against Omicron. Moreover, three-fourths of the doctors (25.8\%) and allied health professionals $(24.8 \%)$ believed that travel bans cannot control the global spread of Omicron, that the COVID19 rapid test is not reliable for detecting Omicron $(40 \%)$, and that steroids cannot treat severe Omicron (doctors: $46.5 \%$ ); moreover, more than half of the HCWs perceived that COVID-19 mutations could alter the response to vaccines, treatment, and transmissibility. However, most of HCWs agreed that vaccinated and unvaccinated people are vulnerable to the Omicron variant. All the HCWs strongly agreed that countries should accelerate the COVID-29 vaccination program (92.6\%).

\subsection{Comparison of HCWs' Knowledge and Perception Scores According to Their Health Specialties}

Overall, doctors outperformed regarding knowledge and perceptions of the Omicron variant compared to other HCWs (Table 3). In the ANCOVA test, there was a statistically significant difference between the health specialties concerning the knowledge category $(p=0.004)$, with a median score of 14 points ( 0 to 20 points) for doctors and 12 points (4 to 20) for medical students, nurses, pharmacists, and allied health professionals. However, no significant difference in perception toward the SARS-CoV-2 Omicron variant was observed between the specialties $(p=0.827)$. 
Table 2. Healthcare professionals' knowledge and Perceptions about the SARS-CoV-2 Omicron.

\begin{tabular}{|c|c|c|c|c|c|c|c|c|c|c|}
\hline $\begin{array}{l}\text { Items Rel } \\
\text { SARS-CoV-2 O }\end{array}$ & $\begin{array}{l}\text { ed to the } \\
\text { icron Vari }\end{array}$ & \multirow{3}{*}{$\begin{array}{l}\text { Medical } \\
\text { Students }\end{array}$} & \multicolumn{4}{|c|}{ Correct Response (\%) } & \multirow{3}{*}{$\begin{array}{l}p \text {-Values } \\
\text { (Male vs. } \\
\text { Female) }\end{array}$} & \multirow[b]{2}{*}{$\begin{array}{l}p \text {-Value } \\
\text { (Doctors } \\
\text { vs. } \\
\text { Others) }\end{array}$} & \multirow[b]{2}{*}{$\begin{array}{c}p \text {-Value } \\
\text { (Attended } \\
\text { vs. Did Not } \\
\text { Attend } \\
\text { Lectures) }\end{array}$} & \multirow[b]{2}{*}{$\begin{array}{c}p \text {-Value } \\
\text { (Developed } \\
\text { vs. } \\
\text { Developing } \\
\text { Country) }\end{array}$} \\
\hline \multirow[t]{2}{*}{ Knowledge } & \multirow{2}{*}{$\begin{array}{l}\text { Doctors } \\
n=430\end{array}$} & & Nurses & Pharmacists & $\begin{array}{l}\text { Allied } \\
\text { Health }\end{array}$ & \multirow[t]{2}{*}{ Variance } & & & & \\
\hline & & & $n=60$ & $n=120$ & $n=105$ & & & & & \\
\hline $\begin{array}{l}\text { The Omicron variant } \\
\text { was first reported to } \\
\text { the World health } \\
\text { organization from } \\
\text { South Africa }\end{array}$ & $\begin{array}{c}328 \\
(76.3)\end{array}$ & $\begin{array}{c}132 \\
(58.7)\end{array}$ & $46(76.7)$ & $73(60.8)$ & $69(65.7)$ & 0.002 & $<0.001$ & 0.001 & 0.010 & $<0.001$ \\
\hline $\begin{array}{c}\text { Skin rash is not a } \\
\text { symptom of Omicron }\end{array}$ & $\begin{array}{c}341 \\
(79.3)\end{array}$ & $\begin{array}{c}163 \\
(72.4)\end{array}$ & $45(75)$ & $83(77.5)$ & $73(69.5)$ & 0.315 & 0.767 & 0.048 & 0.952 & 0.060 \\
\hline $\begin{array}{c}\text { Omicron can be } \\
\text { transmited to all age } \\
\text { groups }\end{array}$ & $\begin{array}{c}402 \\
(93.5)\end{array}$ & $\begin{array}{c}197 \\
(87.6)\end{array}$ & $57(95)$ & $\begin{array}{c}112 \\
(93.3)\end{array}$ & $91(86.7)$ & 0.051 & 0.021 & 0.033 & 0.434 & 0.080 \\
\hline $\begin{array}{l}\text { Wearing a face mask, } \\
\text { hand hygiene, social } \\
\text { distancing, indoor } \\
\text { ventilation, avoiding } \\
\text { crowded places, and } \\
\text { COVID-19 vaccination } \\
\text { can protect from } \\
\text { Omicron }\end{array}$ & $\begin{array}{c}403 \\
(93.5)\end{array}$ & $\begin{array}{c}208 \\
(92.4)\end{array}$ & 57 (95) & $\begin{array}{c}112 \\
(93.3)\end{array}$ & $93(88.6)$ & 0.693 & 0.991 & 0.458 & 0.443 & 0.590 \\
\hline $\begin{array}{l}\text { Taking two doses of } \\
\text { COVID-19 vaccination } \\
\text { is important }\end{array}$ & $\begin{array}{c}394 \\
(91.6)\end{array}$ & $\begin{array}{c}194 \\
(86.2)\end{array}$ & $52(86.7)$ & $\begin{array}{c}108 \\
(90.0)\end{array}$ & $90(85.7)$ & 0.167 & 0.243 & 0.025 & 0.009 & 0.295 \\
\hline \multicolumn{11}{|l|}{ Perceptions } \\
\hline $\begin{array}{l}\text { Currently available } \\
\text { COVID-19 vaccines } \\
\text { offer protection against } \\
\text { Omicron }\end{array}$ & $\begin{array}{c}140 \\
(32.6)\end{array}$ & $74(32.9)$ & $17(28.3)$ & $41(34.2)$ & $34(32.4)$ & 0.888 & 0.177 & 0.978 & 0.855 & 0.326 \\
\hline $\begin{array}{l}\text { A COVID-19 booster } \\
\text { dose offers protection } \\
\text { against Omicron }\end{array}$ & $\begin{array}{c}173 \\
(40.2)\end{array}$ & $92(40.9)$ & $18(30.0)$ & $53(44.2)$ & $39(37.1)$ & 0.331 & 0.149 & 0.606 & 0.269 & 0.906 \\
\hline $\begin{array}{l}\text { COVID-19 mutations } \\
\text { could alter the } \\
\text { response to vaccines, } \\
\text { treatment, and } \\
\text { transmissibility }\end{array}$ & $\begin{array}{c}264 \\
(61.4)\end{array}$ & $\begin{array}{c}112 \\
(49.8)\end{array}$ & $38(63.3)$ & $67(55.8)$ & $60(57.1)$ & 0.044 & 0.516 & 0.030 & 0.244 & 0.954 \\
\hline $\begin{array}{l}\text { Both vaccinated and } \\
\text { unvaccinated people } \\
\text { are vulnerable to } \\
\text { Omicron }\end{array}$ & $\begin{array}{c}388 \\
(90.2)\end{array}$ & $\begin{array}{c}196 \\
(87.1)\end{array}$ & $56(93.3)$ & $\begin{array}{c}104 \\
(86.7)\end{array}$ & $89(84.8)$ & 0.294 & 0.335 & 0.152 & 0.125 & 0.989 \\
\hline $\begin{array}{l}\text { Travel bans cannot } \\
\text { limit the global spread } \\
\text { of Omicron }\end{array}$ & $\begin{array}{c}111 \\
(25.8)\end{array}$ & $48(21.3)$ & $18(30)$ & $18(15)$ & $26(24.8)$ & 0.085 & 0.004 & 0.126 & 0.324 & $<0.001$ \\
\hline $\begin{array}{l}\text { Older people and } \\
\text { people with } \\
\text { comorbidities should } \\
\text { postpone travel }\end{array}$ & $\begin{array}{c}396 \\
(92.1)\end{array}$ & $\begin{array}{c}211 \\
(93.8)\end{array}$ & $54(90)$ & $\begin{array}{c}109 \\
(90.8)\end{array}$ & 95 (90.5) & 0.764 & 0.807 & 0.941 & 0.193 & 0.314 \\
\hline $\begin{array}{c}\text { Steroids are not } \\
\text { effective against severe } \\
\text { Omicron }\end{array}$ & $\begin{array}{c}200 \\
(46.5)\end{array}$ & $\begin{array}{c}114 \\
(50.7)\end{array}$ & $33(55)$ & 69 (57.5) & 72 (68.6) & $<0.001$ & 0.009 & 0.002 & 0.413 & 0.678 \\
\hline $\begin{array}{l}\text { A COVID-19 rapid } \\
\text { antigen test is not } \\
\text { reliable to detect the } \\
\text { Omicron }\end{array}$ & $\begin{array}{c}174 \\
(40.5)\end{array}$ & $\begin{array}{c}100 \\
(44.4)\end{array}$ & 25 (41.7) & $54(45)$ & 44 (41.9) & 0.847 & 0.475 & 0.314 & 0.998 & 0.060 \\
\hline $\begin{array}{c}\text { Face masks offer } \\
\text { protection against all } \\
\text { SARS-CoV-2 variants }\end{array}$ & $370(86)$ & $\begin{array}{c}191 \\
(84.9)\end{array}$ & 46 (76.7) & $\begin{array}{c}104 \\
(86.7)\end{array}$ & 82 (78.1) & 0.122 & 0.501 & 0.192 & 0.419 & 0.125 \\
\hline $\begin{array}{l}\text { Countries should } \\
\text { accelerate the } \\
\text { COVID-19 vaccination } \\
\text { program }\end{array}$ & $\begin{array}{c}405 \\
(94.2)\end{array}$ & $\begin{array}{c}206 \\
(91.6)\end{array}$ & $54(90)$ & $\begin{array}{c}109 \\
(90.8)\end{array}$ & $96(91.4)$ & 0.516 & 0.472 & 0.080 & 0.381 & 0.179 \\
\hline
\end{tabular}


Table 3. ANCOVA test to compare the participants' knowledge and perception score variations across health specialties.

\begin{tabular}{|c|c|c|c|c|c|c|}
\hline & Specialty & Frequency & $\begin{array}{l}\text { Median } \\
\text { (Range) }\end{array}$ & $\mathbf{F}$ & df & $p$-Value \\
\hline \multirow{5}{*}{ Knowledge score } & Doctors & 430 & $14(0-20)$ & \multirow{5}{*}{3.82} & \multirow{5}{*}{4} & \multirow{5}{*}{0.004} \\
\hline & Medical students & 225 & $12(4-20)$ & & & \\
\hline & Nurses & 60 & $12(6-20)$ & & & \\
\hline & Pharmacists & 120 & $12(2-20)$ & & & \\
\hline & Allied Health & 105 & $12(2-20)$ & & & \\
\hline \multirow{5}{*}{ Perception score } & Doctors & 430 & $13(5-18)$ & \multirow{5}{*}{0.374} & \multirow{5}{*}{4} & \multirow{5}{*}{0.827} \\
\hline & Medical students & 225 & $12(6-20)$ & & & \\
\hline & Nurses & 60 & $12(6-18)$ & & & \\
\hline & Pharmacists & 120 & $12(6-20)$ & & & \\
\hline & Allied Health & 105 & $12(4-18)$ & & & \\
\hline
\end{tabular}

The difference is significant at $p=<0.001$. Covariates: age, sex, survey completion time, attended training/discussions regarding Omicron, and developed vs. developing countries.

\subsection{Overall Knowledge and Perception Levels}

The overall knowledge and perception scores for the SARS-CoV-2 Omicron variant statements across the subgroups are shown in Table 4. Based on modified Bloom's criteria, only a quarter (24.3\%) of the HCWs exhibited good knowledge about the Omicron variant, and a majority were male (14\%) and from developing countries $(18.9 \%)$. By contrary, only $20.6 \%$ of the HCWs demonstrated good perception. Moreover, good knowledge and perception were higher among doctors $(13 \%$ and $10 \%)$ than other HCWs. A significant difference in knowledge levels was noted across all subgroups but not in perceptions.

Table 4. Overall knowledge and perception levels across subgroups.

\begin{tabular}{|c|c|c|c|c|c|c|c|c|c|}
\hline \multirow{2}{*}{\multicolumn{2}{|c|}{ Subgroup }} & \multicolumn{3}{|c|}{ Knowledge } & \multirow{3}{*}{$p$-Value } & \multicolumn{3}{|c|}{ Perception } & \multirow{3}{*}{$p$-Value } \\
\hline & & Good & Moderate & Poor & & Good & Neutral & Misperceptions & \\
\hline & Scores & $16-20$ & $12-15$ & $<12$ & & $16-20$ & $12-15$ & $<12$ & \\
\hline Total & $\mathrm{N}=940$ & $228(24.3)$ & 409 (43.5) & $303(32.2)$ & $<0.001$ & $194(20.6)$ & $492(52.3)$ & $254(27)$ & 0.001 \\
\hline \multirow[t]{3}{*}{ Sex } & & & & & 0.624 & & & & 0.913 \\
\hline & Male & $132(14)$ & $240(25.5)$ & $167(17.8)$ & & 109 (11.6) & $285(30.3)$ & $145(15.4)$ & \\
\hline & Female & $96(10.2)$ & $169(18)$ & $136(14.5)$ & & $85(9)$ & $207(22)$ & 109 (11.6) & \\
\hline \multirow[t]{3}{*}{$\begin{array}{c}\text { Age } \\
\text { (years) }\end{array}$} & & & & & 0.002 & & & & 0.132 \\
\hline & $<30$ & $118(12.6)$ & $216(23)$ & $196(20.9)$ & & $97(10.3)$ & $286(30.4)$ & 147 (15.6) & \\
\hline & $\geq 30$ & $110(11.7)$ & $193(20.5)$ & $107(11.4)$ & & $97(10.3)$ & $206(21.9)$ & $107(11.4)$ & \\
\hline \multirow[t]{3}{*}{ Countries } & & & & & $<0.001$ & & & & 0.369 \\
\hline & Developing & $178(18.9)$ & $312(33.3)$ & $266(28.3)$ & & $43(4.6)$ & $98(10.4)$ & $43(4.6)$ & \\
\hline & Developed & $50(5.3)$ & $97(10.3)$ & $37(3.9)$ & & $151(16.1)$ & $394(41.9)$ & $211(22.4)$ & \\
\hline \multirow[t]{6}{*}{ Profession } & & & & & 0.001 & & & & 0.496 \\
\hline & Doctors & $121(12.9)$ & 203 (21.6) & $106(11.3)$ & & $94(10)$ & $227(24.1)$ & 109 (11.6) & \\
\hline & $\begin{array}{l}\text { Medical } \\
\text { students }\end{array}$ & $42(4.5)$ & $87(9.3)$ & $96(10.2)$ & & $46(4.9)$ & 109 (11.6) & $70(7.4)$ & \\
\hline & Nurses & $15(1.6)$ & $27(2.9)$ & $18(1.9)$ & & $12(1.3)$ & $36(3.8)$ & $12(1.3)$ & \\
\hline & Pharmacists & $27(2.9)$ & $50(5.3)$ & $43(4.6)$ & & $18(1.9)$ & $68(7.2)$ & $32(3.6)$ & \\
\hline & Allied health & $23(2.4)$ & $42(4.5)$ & $40(4.3)$ & & $24(2.6)$ & $52(5.5)$ & $29(3.1)$ & \\
\hline
\end{tabular}




\subsection{Predictors of Good Knowledge and Perception}

The multiple logistic regression indicated that HCWs who engaged in training/discussions concerning the SARS-CoV-2 Omicron variant were 1.80 times more likely to have good knowledge and perception than those HCWs who did not attend such trainings/discussions (Table 5). Furthermore, being older (OR: 1.01, 95\% CI: 1.00-1.03), South American (OR: 2.69, 95\% CI: 1.21-6.00), and Oceanic (OR: 2.04, 95\% CI: 1.00-4.16) were significant predictors of higher perception scores. However, HCWs from Africa had significantly lower knowledge and perceptions.

Table 5. Factors associated with good knowledge and perception about the SARS-CoV-2 Omicron.

\begin{tabular}{|c|c|c|c|c|}
\hline \multicolumn{5}{|c|}{ Odds Ratio (95\% Confidence Intervals) } \\
\hline & Categories & Good Knowledge & Good Perception & Both \\
\hline \multirow{2}{*}{ Sex } & Female & 1 & 1 & 1 \\
\hline & Male & $0.93(0.68-1.27)$ & $0.89(0.64-1.24)$ & $0.85(0.49-1.47)$ \\
\hline Age & Years & $1.07(0.99-1.02)$ & $1.01(1.00-1.03) *$ & $1.01(0.99-1.04)$ \\
\hline \multirow{6}{*}{ Location } & Asia & 1 & 1 & 1 \\
\hline & Africa & $0.48(0.26-78)^{* *}$ & $0.55(0.31-0.95) *$ & $0.21(0.05-0.92) *$ \\
\hline & Europe & $1.18(0.76-1.84)$ & $1.14(0.70-1.84)$ & $1.33(0.66-2.68)$ \\
\hline & South America & $1.23(0.53-2.86)$ & $2.69(1.21-6.00) *$ & $1.37(0.37-5.00)$ \\
\hline & North America & $0.53(0.06-4.52)$ & $2.84(0.62-12.91)$ & - \\
\hline & Oceanic & $0.73(0.33-1.63)$ & $2.04(1.00-4.16) *$ & $0.90(0.25-3.22)$ \\
\hline \multirow{5}{*}{ Profession } & Doctors & 1 & 1 & 1 \\
\hline & Medical students & $0.67(0.43-1.04)$ & $1.15(0.70-1.76)$ & $0.85(0.37-1.94)$ \\
\hline & Pharmacists & $0.91(0.48-1.72)$ & $0.86(0.43-1.70)$ & $1.08(0.40-2.96)$ \\
\hline & Nurses & $0.85(0.51-1.42)$ & $0.72(0.40-1.30)$ & $0.59(0.19-1.81)$ \\
\hline & Allied health & $0.77(0.46-1.29)$ & $1.07(0.64-1.80)$ & $0.78(0.31-1.95)$ \\
\hline \multirow{2}{*}{$\begin{array}{l}\text { Engaged in Omicron-related } \\
\text { training/discussions }\end{array}$} & No & 1 & 1 & 1 \\
\hline & Yes & $1.72(1.27-2.38)^{* *}$ & $0.98(0.70-1.38)$ & $1.80(1.04-3.11)^{* *}$ \\
\hline
\end{tabular}

Adjusted: age, gender, location, profession, and engaged in training/discussion. ${ }^{*} p<0.05 ;{ }^{* *} p<0.01$.

\section{Discussion}

The SARS-CoV-2 Omicron variant is a hot topic of discussion among the public, especially among HCWs. This is the first study exploring HCWs' understanding of the SARS-CoV-2 Omicron variant. The findings indicate that most health professionals have a comparable level of knowledge of this new variant, despite differences in knowledge and perception based on the region of practice. The Omicron variant has a high transmissibility rate-current figures indicate that it has reached ten times the number reported during the peak of the Delta wave [25] — creating an unprecedented burden to health officials and health systems. At present, the Omicron variant is causing a whirlwind worldwide, with thousands of cases reported every day, with no exemptions for COVID-19 vaccinated people [26]. To the authors' knowledge, this study, for the first time, examined the basic professional knowledge and perception concerning the SARS-CoV-2 Omicron variant among HCWs.

The data from this international cross-sectional study indicate that HCWs are largely aware of the Omicron variant, but only a third (36.3\%) of them had the opportunity to engage in lectures or discussions related to this new variant. We also found that a quarter of HCWs $(24.3 \%)$ used official governmental websites as their go-to place as a primary source of information about Omicron. This study showed that HCWs reported having insufficient knowledge and some misperceptions, and there was a significant difference 
in knowledge levels across different categories of HCWs. This research also showed that $32 \%$ and $27 \%$ of the participants experienced poor knowledge and misperceptions towards the Omicron variant, respectively. Finally, this study showed that engaging in Omicronrelated training/discussions was strongly associated with greater knowledge and improved perceptions of HCWs.

Knowledge about the Omicron variant varied significantly across the countries of the participants: those from developed countries had a higher overall score than their counterparts from non-developed countries. This difference could be for several reasons. For example, the lack of adequate infrastructure to enable adequate health responses to the pandemic, including a poor health communication strategy, could contribute to limited access to reliable information sources. In addition, other competing priorities in several developing settings such as socioeconomic crises that occur due to or are exacerbated by COVID-19 could divert the attention of communities, leading to complacency and poor uptake of health directions. Misinformation and disinformation are also contributing factors that amplify mistrust and impair health responses [27] -and this is likely to be more significant in settings with poor health communication strategies in place. Finally, COVID-19 fatigue or exhaustion due to the continually emerging variants and the need to adjust to these new realities is another potential contributing factor leading to complacency and poor response to emerging variants. However, this could apply to both developed and developing settings [28].

The poorer knowledge reported in developing settings could be, understandably, associated with lack of sufficient resources and means to sustainably fight this disease. The need for ongoing education and training of health professionals is resource-intensive, and developing settings may not be able to afford to provide them for a long time amidst ongoing competing health priorities. The World Health Organization (WHO) and other multilateral institutions have ongoing education, training, [29,30] and workshops on new developments in COVID-19 and available vaccines. However, national ministries and other relevant health authorities in individual countries have a significant responsibility to provide culturally and locally appropriate training and education to enable their health workforce to adequately tackle current and potential future variants. There is no doubt that the major challenge remains to address the significant inequity in vaccine distribution between the global south and north. However, improving the competency and preparedness of healthcare workers through appropriate training will be valuable in creating resilient health systems.

Due to the overwhelming number of cases of Omicron reported across the globe, many health systems are struggling to cope with the significant surge in demand for health needs. This must be seen in the context that health workers are highly likely to experience more severe COVID-19 cases [31]. Despite being characterized as "mild" in most settings, the Omicron variant still places considerable pressure on health systems [32], particularly making settings with low vaccination rates more exposed to the clinical and social consequences of the disease. Therefore, it is important to understand the differences between this particular variant and the previous ones and to clear some misperceptions related to the disease in an ongoing manner. Interestingly, our findings indicate that the probability of HCWs to identify VOCs and their reported places of origin has increased over time since the origin of COVID-19, potentially indicating an increased readiness of health professionals to become involved in knowing more about emerging variants. We also anticipate this to be the case with the wider public. Nevertheless, it is imperative to target HCWs through appropriate continuing education programs to equip them with the relevant knowledge to enable them to respond to the health crisis confidently and be able to educate vulnerable communities.

Generally, most participants had good knowledge about the individual measures to prevent and control the spreading of the SARS-CoV-2 Omicron variant and emphasized the importance of receiving two doses of the COVID-19 vaccine. However, wide discrepancies were identified in the perceptions of different categories of HCWs. For instance, 85\% of the 
pharmacists and $74.2 \%$ of the doctors believed that the travel bans could limit the global spread of Omicron. Since the Omicron variant has already spread worldwide, travel bans go against WHO COVID-19 recommendation to apply a risk-based scientific approach when implementing specific travel measures and recommendations for reducing risk acquisition or spread of the virus [2]. Moreover, more than half of the doctors (53.5\%) believed that steroidal therapy is effective against severe Omicron cases. The Omicron variant has numerous mutations in the spike protein (S-gene) [33], and drugs used in severe COVID-19 cases such as corticosteroids and interleukin-6 receptor blockers may not effectively target the spike protein in severe Omicron. Finally, a vast majority of HCWs strongly agreed that countries should accelerate the COVID-19 vaccination program (over 90\%). Moreover, HCWs strongly recommended that older people and those with comorbidities should be advised to postpone travel to areas with community transmission.

\section{Strengths and Limitations}

Responses obtained through online surveys are less reliable and accountable. However, given the pandemic situation, web-based design in medical research is growing. Our study is novel and it engaged HCWs from multiple countries to explore their knowledge and perceptions on SARS-CoV-2 Omicron. The large number of study participants $(\mathrm{n}=940)$ and the high participation rate $(89 \%)$ covering 101 countries across the six continents added significant strength. In addition, the survey tool was developed based on the WHO and CDC briefing materials for the detection, prevention, and control of the SARS-CoV-2 Omicron variant. The questionnaire developed was pilot tested, used close-ended questions to reduce information bias, and covered a wide range of Omicron-related topics, enabling us to explore the participants' knowledge and perception multidimensionally. Moreover, we used the Qualtrics online software to obtain the responses within a 30 min window of time. The study collected specific demographic data to perform stratified comparison analyses.

However, this study has some limitations that should be considered. This research is a cross-sectional study conducted among HCWs during the second week of January 2022, when an alarming number of Omicron cases were being reported globally. The data presented in this study are self-reported and rely on participants' honesty and recall ability. Thus, they may be subjected to recall bias. Moreover, the survey was conducted during the early stage of the Omicron epidemic, and thus, many of them may have had little or no knowledge about this new variant. Furthermore, factors such as internet access, variation in time, and language barriers may have influenced study participation. Despite these limitations, the findings from this study provide valuable information about HCWs' knowledge and perceptions about Omicron during the peak stage of the pandemic.

\section{Conclusions}

This study found significant gaps in HCWs' knowledge and significant misperceptions about the SARS-CoV-2 Omicron variant. As the world is experiencing a large wave of SARS$\mathrm{CoV}-2$ Omicron variant infections, which is inexorably reaching every continent, greater efforts through educational interventions targeting HCWs and the general population are urgently needed to improve their knowledge and perceptions of the SARS-CoV-2 Omicron variant.

Supplementary Materials: The following supporting information can be downloaded at https:// www.mdpi.com/article/10.3390/healthcare10030438/s1, Supplemental File S1: survey questionnaire; Supplemental Figure S1: sample size; Supplemental Table S1: CHERRIES checklist.

Author Contributions: Conceptualization, A.S.B.; methodology, A.S.B.; software, A.S.B.; validation, A.S.B., W.T., K.R.N. and V.K.C.; formal analysis, A.S.B.; investigation, A.S.B. and M.A.M.; resources, M.A.M.; data curation, A.S.B. and M.A.M.; writing-original draft preparation, A.S.B. and W.T.; writing-review and editing, W.T. and V.K.C.; visualization, A.S.B.; supervision, V.K.C.; project administration, M.A.M. and K.R.N.; funding acquisition, none. All authors have read and agreed to the published version of the manuscript. 
Funding: This research received no external funding.

Institutional Review Board Statement: The study was conducted in accordance with the Declaration of Helsinki, and approved by the Institutional Ethical Committee of Ananthapuri Hospitals and Research Institute (AHRI/EC/Dec/2021), India, on 21 December 2021.

Informed Consent Statement: Electronic informed consent was obtained from all subjects involved in the study.

Data Availability Statement: All the data presented in this study are available upon request from the corresponding author.

Acknowledgments: We thank all study participants for their voluntary participation and for providing essential information.

Conflicts of Interest: The authors declare no conflict of interest.

\section{References}

1. John Hopkins, C. Coronavirus COVID-19 (2019-nCoV). 2020. Available online: https://www.arcgis.com/apps/dashboards / bda7594740fd40299423467b48e9ecf6 (accessed on 15 February 2022).

2. WHO. 2021c WHO 2nd Global Consultation on Assessing the Impact of SARS-CoV-2 Variants of Concern on Public Health Interventions. Available online: https:/ / www.who.int/publications/m/item/2nd-global-consultation-on-assessing-theimpactof-sars-cov-2-variants-of-concern-on-public-health-interventions (accessed on 14 January 2022).

3. Dolgin, E. Omicron thwarts some of the world's most-used COVID vaccines. Nature 2022, 601, 311. [CrossRef] [PubMed]

4. Robinson, M.L.; Morris, C.P.; Betz, J.; Zhang, Y.; Bollinger, R.; Wang, N.; Thiemann, D.R.; Fall, A.; Eldesouki, R.E.; Norton, J.M.; et al. Impact of SARS-CoV-2 variants on inpatient clinical outcome. medRxiv 2022, 2022, 22270337. [CrossRef]

5. Ledford, H. How severe are Omicron infections? Nature 2021, 600, 577-578. [CrossRef]

6. Sheikh, A.; Kerr, S.; Woolhouse, M.; McMenamin, J.; Robertson, C. Severity of Omicron Variant of Concern and Vaccine Effectiveness against Symptomatic Disease: National Cohort with Nested Test Negative Design Study in Scotland. 2021. Available online: https://www.pure.ed.ac.uk/ws/portalfiles/portal/245818096/Severity_of_Omicron_variant_of_concern_ and_vaccine_effectiveness_against_symptomatic_disease.pdf (accessed on 20 December 2021).

7. Polack, F.P.; Thomas, S.J.; Kitchin, N.; Absalon, J.; Gurtman, A.; Lockhart, S.; Perez, J.L.; Pérez Marc, G.; Moreira, E.D.; Zerbini, C.; et al. C4591001 Clinical Trial Group. Safety and Efficacy of the BNT162b2 mRNA COVID-19 Vaccine. N. Engl. J. Med. 2020, 383, 2603-2615. [CrossRef]

8. Baden, L.R.; El Sahly, H.M.; Essink, B.; Kotloff, K.; Frey, S.; Novak, R.; Diemert, D.; Spector, S.A.; Rouphael, N.; COVE Study Group. Efficacy and Safety of the mRNA-1273 SARS-CoV-2 Vaccine. N. Engl. J. Med. 2021, 384, 403-416. [CrossRef] [PubMed]

9. Voysey, M.; Clemens, S.A.C.; Madhi, S.A.; Weckx, L.Y.; Folegatti, P.M.; Aley, P.K.; Angus, B.; Baillie, V.L.; Barnabas, S.L.; Bhorat, Q.E.; et al. Safety and efficacy of the ChAdOx1 nCoV-19 vaccine (AZD1222) against SARS-CoV-2: An interim analysis of four randomised controlled trials in Brazil, South Africa, and the UK. Lancet 2021, 397, 99-111. [CrossRef]

10. Khoury, D.S.; Steain, M.; Triccas, J.A.; Sigal, A.; Davenport, M.P.; Cromer, D. A meta-analysis of early results to predict vaccine efficacy against Omicron. medRxiv 2021, 12, 21267748. [CrossRef]

11. Israel, A.; Merzon, E.; Schäffer, A.A.; Shenhar, Y.; Green, I.; Golan-Cohen, A.; Ruppin, E.; Magen, E.; Vinker, S. Elapsed time since BNT162b2 vaccine and risk of SARS-CoV-2 infection: Test negative design study. BMJ 2021, 375, e067873. [CrossRef]

12. Callaway, E.; Ledford, H. How bad is Omicron? What scientists know so far. Nature 2021, 600, 197-199. [CrossRef]

13. Pajon, R.; Doria-Rose, N.A.; Shen, X.; Schmidt, S.D.; O’Dell, S.; McDanal, C.; Feng, W.; Tong, J.; Eaton, A.; Maglinao, M.; et al. SARS-CoV-2 Omicron Variant Neutralization after mRNA-1273 Booster Vaccination. N. Engl. J. Med. 2022. [CrossRef]

14. Bhagavathula, A.S.; Aldhaleei, W.A.; Rahmani, J.; Mahabadi, M.A.; Bandari, D.K. Knowledge and Perceptions of COVID-19 Among Health Care Workers: Cross-Sectional Study. JMIR Public Health Surveill. 2020, 6, e19160. [CrossRef] [PubMed]

15. Gambhir, R.S.; Dhaliwal, J.S.; Aggarwal, A.; Anand, S.; Anand, V.; Kaur Bhangu, A. COVID-19: A survey on knowledge, awareness and hygiene practices among dental health professionals in an Indian scenario. Rocz. Panstw. Zakl. Hig. 2020, 71, 223-229. [CrossRef]

16. Zhang, M.; Zhou, M.; Tang, F.; Wang, Y.; Nie, H.; Zhang, L.; You, G. Knowledge, attitude, and practice regarding COVID-19 among healthcare workers in Henan, China. J. Hosp. Infect. 2020, 105, 183-187. [CrossRef]

17. Masoud, A.T.; Zaazouee, M.S.; Elsayed, S.M.; Ragab, K.M.; Kamal, E.M.; Alnasser, Y.T.; Assar, A.; Nourelden, A.Z.; Istatiah, L.J.; KAP-COVIDGLOBAL Investigators. KAP-COVIDGLOBAL: A multinational survey of the levels and determinants of public knowledge, attitudes and practices towards COVID-19. BMJ Open 2021, 11, e043971. [CrossRef] [PubMed]

18. Siddiquea, B.N.; Shetty, A.; Bhattacharya, O.; Afroz, A.; Billah, B. Global epidemiology of COVID-19 knowledge, attitude and practice: A systematic review and meta-analysis. BMJ Open 2021, 11, e051447. [CrossRef]

19. WHO. Coronavirus Update 70: Update on SARS-CoV-2 Variant of Concern Omicron. Available online: https://www.who.int/ docs/default-source/coronaviruse/risk-comms-updates/update70_omicron.pdf?sfvrsn=eaf76988_5 (accessed on 10 December 2021). 
20. CDC. Update on Omicron Variant. Available online: https://www.cdc.gov/vaccines/acip/meetings/downloads/slides-2021-1 2-16/06-COVID-Scobie-508.pdf (accessed on 17 December 2021).

21. CDC. Science Brief: Omicron (B.1.1.529) Variant. Available online: https://www.cdc.gov/coronavirus/2019-ncov/science/ science-briefs/scientific-brief-omicron-variant.html (accessed on 12 December 2021).

22. Faul, F.; Erdfelder, E.; Buchner, A.; Lang, A.G. Statistical power analyses using G*Power 3.1: Tests for correlation and regression analyses. Behav. Res. Methods 2009, 41, 1149-1160. [CrossRef]

23. Armstrong, P.; Bloom's Taxonomy. Vanderbilt University Center for Teaching. Available online: https://cft.vanderbilt.edu/ guides-sub-pages/blooms-taxonomy.htm (accessed on 15 December 2021).

24. Eysenbach, G. Improving the quality of Web surveys: The Checklist for Reporting Results of Internet E-Surveys (CHERRIES). J. Med. Internet Res. 2004, 6, e34. [CrossRef]

25. Murray, C.J.L. COVID-19 will continue but the end of the pandemic is near. Lancet 2022, 399, 417-419. [CrossRef]

26. Hoffmann, M.; Krüger, N.; Schulz, S.; Cossmann, A.; Rocha, C.; Kempf, A.; Nehlmeier, I.; Graichen, L.; Moldenhauer, A.S.; Winkler, M.S.; et al. The Omicron variant is highly resistant against antibody-mediated neutralization: Implications for control of the COVID-19 pandemic. Cell 2022, 185, 447-456.e11. [CrossRef] [PubMed]

27. OECD Policy Responses to Coronavirus (COVID-19). Transparency, Communication and Trust: The Role of Public Communication in Responding to the Wave of Disinformation about the New Coronavirus. Available online: https: //www.oecd.org/coronavirus / policy-responses/transparency-communication-and-trust-the-role-of-public-communicationin-responding-to-the-wave-of-disinformation-about-the-new-coronavirus-bef7ad6e/ (accessed on 19 January 2022).

28. World Health Organization (WHO). Pandemic Fatigue-Reinvigorating the Public to Prevent COVID-19. Policy Framework for Supporting Pandemic Prevention and Management; WHO Regional Office for Europe: Copenhagen, Denmark, 2020; Available online: https:/ / apps.who.int/iris/bitstream/handle/10665/335820/WHO-EURO-2020-1160-40906-55390-eng.pdf (accessed on 19 February 2022).

29. World Health Organization. Coronavirus Disease (COVID-19) Training: Online Training. Available online: https:/ /www.who. int/emergencies/diseases/novel-coronavirus-2019/training/online-training (accessed on 19 February 2022).

30. United Nations. Sharpen Your Skills during Lockdown with UN e-Learning Courses. Available online: https:/ /unric.org/en/ sharpen-your-skills-during-lockdown-with-united-nations-e-learning-courses/ (accessed on 19 February 2022).

31. Mutambudzi, M.; Niedwiedz, C.; Macdonald, E.B.; Leyland, A.; Mair, F.; Anderson, J.; Celis-Morales, C.; Cleland, J.; Forbes, J.; Gill, J.; et al. Occupation and risk of severe COVID-19: Prospective cohort study of 120075 UK Biobank participants. Occup. Environ. Med. 2020, 78, 307-314. [CrossRef]

32. World Health Organization (Europe). The Omicron Variant: Sorting Fact from Myth. Available online: https://www.euro.who. int/en/health-topics/health-emergencies/pages/news/news/2022/01/the-omicron-variant-sorting-fact-from-myth (accessed on 20 January 2022).

33. Kannan, S.; Ali, P.S.S.; Sheeza, A. Omicron (B.1.1.529)—Variant of concern-Molecular profile and epidemiology: A mini review. Eur. Rev. Med. Pharmacol. Sci. 2021, 25, 8019-8022. [CrossRef] [PubMed] 